\title{
CHRONIC CALCULUS CHOLECYSTITIS IN THE PEOPLE OF BARAK VALLEY IN RELATION TO SEX, AGE AND NUMBER OF GALL BLADDER STONES- AN OBSERVATIONAL STUDY
}

\author{
Bikash Sandalya ${ }^{1}$
}

${ }_{1}^{1}$ Assistant Professor, Department of General Surgery, Silchar Medical College and Hospital.

ABSTRACT
BACKGROUND
Gallstone disease is responsible for morbidities and mortality all across the globe. Cholecystitis means inflammation of the gall
bladder. It is one of the most common conditions, which is encountered by a surgeon in the North East region. Chronic cholecystitis
is a long-standing gallbladder inflammation, which occurs almost always due to gallstones.
The aim of this study is to find the correlation of chronic calculus cholecystitis with the gender and age of the patients as well as
with the number of stones.

\section{MATERIALS AND METHODS}

This prospective observational study was conducted over a period of three years from July 2014 to June 2017 in the Department of General Surgery, Silchar Medical College and Hospital, Silchar, Barak Valley, Assam. 900 patients who were admitted for elective cholecystectomy in the department during this period were studied.

\section{RESULTS}

Of the 900 patients, 243 were males and 656 were females. Male-to-female ratio was 1: 2.7. All the histopathological lesions were also found to be predominant in the female population. Maximum patients in the study group belonged to the age group $31-40$ years. Mean age of chronic cholecystitis was 39.48 years and acute on chronic cholecystitis 41.63 years. 576 patients had multiple stones and 324 patients had single stone when analysed. The ' $p$ ' value was found to be significant $(<0.001)$.

\section{CONCLUSION}

Cases of chronic calculus cholecystitis are frequently encountered by a surgeon in his day-to-day practice. Almost all studies have reported female sex predilection apart from higher distribution in the fourth to fifth decade of life. Symptomatic gallstone disease are found more often in association with multiple calculi. Future research should be directed towards preventing the onset of gallstone formation by identifying the at-risk population.

\section{KEYWORDS}

Chronic Calculus Cholecystitis, Age, Sex, Number of Gallbladder Stones.

HOW TO CITE THIS ARTICLE: Sandalya B. Chronic calculus cholecystitis in the people of Barak valley in relation to sex, age and number of gall bladder stones- an observational study. J. Evolution Med. Dent. Sci. 2018;7(07):850-852, DOI: $10.14260 /$ jemds/2018/193

\section{BACKGROUND}

Cholecystitis means inflammation of the gall bladder. It is one of the most common conditions, which is encountered by a surgeon in the North East region. Chronic cholecystitis is long-standing gallbladder inflammation, which occurs almost always due to gallstones. Gallstones are formed as a result of concretion of the bile constituents; majority of these being cholesterol stones. They are responsible for bringing about histopathological changes in the gallbladder mucosa, sometimes even predisposing to malignancy. Cholelithiasis is common with the incidence ranging from $10 \%$ to $20 \%$ of the world's population, $11 \%$ of the general population of the US.[1] The estimated prevalence of gallstone disease in India has been reported as $2 \%$ to $29 \%$.[2,3] This disease is seven times more common in the North (stone belt) than in South India. ${ }^{[4]}$

'Financial or Other Competing Interest': None.

Submission 05-01-2018, Peer Review 31-01-2018,

Acceptance 06-02-2018, Published 12-02-2018.

Corresponding Author:

Dr. Bikash Sandalya,

Assistant Professor,

Department of General Surgery,

Silchar Medical College and Hospital.

E-mail: bikashsandilya@gmail.com

DOI: $10.14260 / \mathrm{jemds} / 2018 / 193$

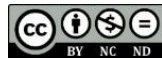

The prevalence varies with age, sex and ethnic group.[5] Incidence of gallstone increases with age. It is common in females than males.[5,6] The average age of these patients in India is a decade younger than those in the West.[7]

The present study was taken up with the aim to find the distribution of chronic calculus cholecystitis in relation to sex, age and number of stones.

\section{MATERIALS AND METHODS}

This prospective, observational study was carried out in the Department of General Surgery, Silchar Medical College Hospital. The duration of the study being three years from July 2014 to June 2017. The sample size was considered conveniently.

All the 900 cases with diagnosed chronic calculus cholecystitis reporting to the surgical outpatient department were taken for the study. The exclusion criteria for the study were patients with acute attack of cholecystitis pain for the first time, patients with acalculus cholecystitis, patients with malignant gallbladder proved post-operatively after histopathology and those who were unfit for surgery.

All patients with ultrasonographically diagnosed chronic calculus cholecystitis were subjected to all necessary preoperative investigations. After counselling and taking consent for surgery, either laparoscopic or open cholecystectomy was performed. All cases were done under general anaesthesia. 
The gall bladder resected was morphologically assessed. The thickness of the gallbladder wall was measured from the area that showed maximum thickness in mm using a caliper.

Further the specimen was fixed in $10 \%$ buffered formaldehyde and sent for histopathological examination. The specimen was embedded in paraffin and cut in $5 \mu \mathrm{m}$ thin slices and stained with haematoxylin and eosin.

The cases with histopathological features of chronic cholecystitis and acute on chronic cholecystitis were taken for our study.

- Chronic Cholecystitis: Composed predominantly of T lymphocytes along with some plasma cells, histiocytes and occasional eosinophils. They also showed chronic changes such as fibrosis and thickening.

- Acute on Chronic Cholecystitis: These cases showed intraepithelial aggregates of neutrophils, widespread fibroblastic proliferation interposed on chronic inflammatory changes.

The histopathological and morphological characters of gallbladder were compared with sex of the patient, age and the number of gallstones, and the results were statistically analysed.

\section{RESULTS}

A total of 900 gallbladder specimens of patients who underwent elective cholecystectomy were analysed. The changes in mucosa for chronic calculus cholecystitis were studied to find out if any correlation existed between chronic calculus cholecystitis and sex, age and number of stones.

\section{Sex Distribution and Chronic Calculus Cholecystitis}

Out of the 900 patients, 243 were males and 657 were females. Male-to-female ratio was 1:2.7. All the histopathological lesions were also found to be predominant in the female population (Table 1).

\section{Relation between Chronic Cholecystitis and Age Distribution}

Maximum patients in the study group belonged to the age group 31 to 40 years. The youngest patient was a 6-year-old female and the eldest was an 82-year-old male, both diagnosed as chronic cholecystitis. Mean age of chronic cholecystitis was 39.48 years and that of acute on chronic cholecystitis was 41.63 years (Table 2).

\section{Relation between Chronic Calculus Cholecystitis and Number of Stones}

Of the total 900 patients, 576 patients had multiple stones and 324 patients had single stone when analysed (Table 3). The ' $p$ ' value was found to be significant $(<0.001)$.

\begin{tabular}{|c|c|c|c|}
\hline \multirow{2}{*}{ Gallbladder Histopathology } & \multicolumn{2}{|c|}{ Sex } & \multirow{2}{*}{ Total } \\
\cline { 2 - 3 } & $\begin{array}{c}\text { Male N } \\
\text { (\%) }\end{array}$ & $\begin{array}{c}\text { Female } \\
\text { N (\%) }\end{array}$ & \\
\hline Chronic Cholecystitis & $\begin{array}{c}243 \\
(27 \%)\end{array}$ & $\begin{array}{c}657 \\
(73 \%)\end{array}$ & 900 \\
\hline \multicolumn{3}{|c|}{ Table 1: Sex distribution of chronic calculus cholecystitis } \\
\hline
\end{tabular}

\begin{tabular}{|c|c|c|c|c|c|c|c|c|c|c|c|}
\hline \multirow{2}{*}{$\begin{array}{c}\text { Gallbladder } \\
\text { Histopathology }\end{array}$} & \multicolumn{9}{|c|}{ Age Interval (years) } & \multirow[t]{2}{*}{ Total } & \multirow[t]{2}{*}{ Mean } \\
\hline & 1-10 & 11-20 & $21-30$ & $31-40$ & $41-50$ & $51-60$ & 61-70 & 71-80 & 81-90 & & \\
\hline $\begin{array}{c}\text { Chronic } \\
\text { Cholecystitis } \\
\text { N (\%) }\end{array}$ & $9(1 \%)$ & $\begin{array}{c}72 \\
(8 \%)\end{array}$ & $\begin{array}{c}207 \\
(23 \%)\end{array}$ & $\begin{array}{c}234 \\
(26 \%)\end{array}$ & $\begin{array}{c}183 \\
(20.3 \%)\end{array}$ & $\begin{array}{c}126 \\
(14 \%)\end{array}$ & $\begin{array}{c}60 \\
(6.7 \%)\end{array}$ & $6(0.7 \%)$ & $3(0.3 \%)$ & 900 & 39.48 \\
\hline
\end{tabular}

\begin{tabular}{|c|c|c|c|}
\hline \multirow{2}{*}{ Gallbladder Histopathology } & \multicolumn{2}{|c|}{ No. of Stones } & \multirow{2}{*}{ Total } \\
\cline { 2 - 3 } & Multiple & Single & \\
\hline Chronic Cholecystitis N (\%) & $\begin{array}{c}576 \\
(64 \%)\end{array}$ & $\begin{array}{c}324 \\
(36 \%)\end{array}$ & \multirow{2}{*}{900} \\
\hline \multicolumn{3}{|c|}{ Table 3. Distribution of chronic calculus cholecystitis } \\
according to the number of gallbladder stones \\
\hline
\end{tabular}

\section{DISCUSSION}

A 2.7 fold higher incidence of chronic calculus cholecystitis was observed among female patients compared to male patients in our study. Several authors have reported a female predominance of cholelithiasis and gall bladder pathologies in their studies. ${ }^{[8,9,10,11,12,13,14]}$ The female sex hormones and sedentary lifestyle of Indian women may expose them to factors promoting formation of gallstones.[7,9,15,16,17] Oestrogen is believed to stimulate the HMG-CoA reductase leading to increased synthesis of cholesterol and progesterone is believed to reduce the gallbladder motility promoting bile stasis and concretion. Post-menopausal women who are prescribed hormone replacement therapy have also reported higher incidence of gallbladder calculi.
In the present study, chronic cholecystitis was found to be higher in the age group 31 - 40 years with a mean age of 39.48 years similar to another study.[18]

The age distribution showed similar observations with maximum population between 30 to 39 years with a mean of $41.70+/-14.64$ years in one study[19] and 35 to 45 years in another study.[13] The mean age was 45.90 years[14] and 45.90[15] in other studies. Two studies have reported peak age of incidence as 41 - 50 years.[20,21] In one study, the commonest age group for cholelithiasis was below 30 years comprising 37.5\%.[22] Studies have shown an increase in the prevalence of gallstones with age probably because of decrease in activity of cholesterol á reductase and increase in activity of HMG-CoA reductase resulting in increased cholesterol secretion and saturation of bile. ${ }^{[4,16]}$

As regards the number of stones, other studies have showed a predominance of multiple gallstones in the gall bladder lesions,[23,24] similar to our study. This indicates that cases having multiple stones are more symptomatic (cholecystitis) than with single stone. 


\section{CONCLUSION}

Cases of chronic calculus cholecystitis are frequently encountered by a surgeon in his day-to-day practice. Almost all studies have reported female sex predilection apart from higher distribution in the fourth to fifth decade of life. Symptomatic gallstone disease are found more often in association with multiple calculi. Future research should be directed towards preventing the onset of gallstone formation by identifying the at-risk population.

\section{REFERENCES}

[1] Coelho JC, Bonilha R, Pitaki SA, et al. Prevalence of gallstone in Brazilian population. Int Surg 1999;84(1):25-8.

[2] Prakash A. Chronic cholecystits and cholelithiasis in India. Int Surg 1968;49:79-85.

[3] Khuroo MS, Mahajan R, Zargar SA, et al. Prevalence of biliary tract disease in India: a sonographic study in adult population in Kashmir. Gut 1989;30(2):201-5.

[4] Jayanthi V, Palanivelu C, Prasanthi R, et al. Composition of gallstones in Coimbatore district of Tamil Nadu state. Ind J Gastroenterol 1998;17(4): 134-5.

[5] Johnston DE, Kaplan MM. Pathogenesis and treatment of gallstones. New Engl J Med 1993;328(6):412-21.

[6] Diehl AK. Epidemiology and natural history of gallstone disease. Gastroenterol Clin North Am 1991;20(1):1-19.

[7] Tandon RK. Pathogenesis of gallstones in India. Trop Gastroenterol 1988;9(2):83-93.

[8] Mohan H, Punia RPS, Dhawan SB, et al. Morphological spectrum of gallstone disease in 1100 cholecystectomies in north India. Indian J Surg 2005;67(3):140-2.

[9] Tyagi SP, Tyagi N, Maheshwari Y, et al. Morphologic changes in diseased gall bladder: a study of 415 cholecystectomies at Aligarh. J Indian Med Assoc 1992;90(7):178-81.

[10] Khanna R, Chansuria R, Kumar M, et al. Histological changes in gall bladder due to stone disease. Indian J Surg 2006;68(4):201-4.

[11] Singh UR, Agarwal S, Misra K. Histopathological study of xanthogranulomatous cholecystitis. Indian J Med Res 1989;90:285-8.
[12] Badke A, Schwenk W, Bohm B, et al. Histopathological changes of gallbladder and liver parenchyma in symptomatic cholelithiasis. Dtsch Med Wochenschr 1993;118(22):809-13.

[13] Gupta SC, Misra V, Singh PA, et al. Gall stones and carcinoma gall bladder. Indian J Pathol Microbiol 2000;43(2):147-54.

[14] Selvi RT, Sinha P, Subramaniam PM, et al. A clinicopathological study of cholecystitis with special reference to analysis of cholelithiasis. IJBMS 2017;7(5).

[15] Mathur SK, Duhan A, Singh S, et al. Correlation of gallstone characteristics with mucosal changes in gall bladder. Trop Gastroenterol 2012;33(1):39-44.

[16] Baig SJ, Biswas S, Das S, et al. Histopathological changes in gallbladder mucosa in cholelithiasis: correlation with chemical composition of gallstones. Trop Gastroenterol 2002;23(1):25-7.

[17] Dhar SC, Ansari S, Saha M, et al. Gallstone disease in a rural Bangladeshi community. Ind J Gastroenterol 2001;20(6):223-6.

[18] Bockus HL, Chapman MJ, Worobetz LJ, et al. Symptomatic gall stone disease in Spanish population. J Gastroenterol 2004;39:576-84.

[19] Goyal S, Singla S, Duhan A. Correlation between gallstones characteristics and gallbladder mucosal changes: a retrospective study of 313 patients. Clin Cancer Investig J 2014;3(2):157-61.

[20] Zuhair R, Bahrani A, Mohammad R, et al. Prevalence and morphology and chemical composition of gallstones. Iraqi Post Graduate Medical Journal 2011;10:1.

[21] Ransohoff DF, Gracie WA. The natural history of silent gallstones: the innocent gallstone is not a myth. N Eng J Med 1982:307(13):798-800.

[22] Maskey CP, Shrestha ML, Sato Y. Gallstone in TUTH. JIOM 1990;12:45-54.

[23] Domeyer PJ, Sergentanis TN, Zagouri F, et al. Chronic cholecystitis in elderly patients. Correlation of the severity of inflammation with the number and size of the stones. In Vivo 2008;22(2):269-72.

[24] Juvonen T, Niemela O, Makela J, et al. Characteristics of symptomatic gallbladder disease in patients with either solitary or multiple cholesterol gallstones. Hepatogastroenterology 1994;41(3):263-6. 